(2) Open Access Full Text Article

\title{
Pregnancy complicated by morbidly adherent placenta in a patient with bilateral ovarian agenesis: a case report
}

This article was published in the following Dove Press journal:

International Journal of Women's Health

4 February 2013

Number of times this article has been viewed

Hong Soo Wong

Australian Women's Ultrasound

Centre, Brisbane, Australia
Correspondence: Hong Soo Wong PO Box 8223, Sunnybank, Queensland 4109, Australia

Tel +6I 733233380

Fax +6I 733233381

Email hsoowong@netvigator.com

\begin{abstract}
The author presents a case of in vitro fertilization pregnancy complicated by morbidly adherent placenta in a patient with congenital bilateral ovarian agenesis. A 31-year-old woman with congenital bilateral ovarian agenesis who had undergone two previous dilatation and curettage procedures conceived following in vitro fertilization with a donor egg. Spontaneous labor occurred at 38 weeks and 5 days' gestation. The labor was augmented in the active phase and resulted in instrumental vaginal delivery. The third stage was complicated by hemorrhage and retained placenta. Morbidly adherent placenta was diagnosed on attempt at manual removal of the placenta, and the adherent part of the placenta was left in situ. This was removed uneventfully at 5 weeks following childbirth when there was no blood flow observed between the placenta and the myometrium on Doppler ultrasound examination. In conclusion, successful parturition is possible in patients with congenital bilateral ovarian agenesis. When morbidly adherent placenta is managed conservatively, the placenta may be safely removed if there is no vascularity between the placenta and the myometrium.
\end{abstract}

Keywords: IVF, placenta accreta, parturition, myometrium

\section{Introduction}

Congenital bilateral ovarian agenesis is a rare condition, and pregnancy was not anticipated for those with this condition before the era of assisted reproduction. To the best of the author's knowledge, this is the second case in the literature of a pregnancy resulting from in vitro fertilization (IVF) in a patient with congenital bilateral ovarian agenesis. ${ }^{1}$ Unfortunately, this pregnancy was complicated by morbidly adherent placenta (or placenta accreta); the case highlighted the possible association of morbidly adherent placenta with pregnancy achieved through assisted reproduction. ${ }^{2}$ The management of morbidly adherent placenta will also be discussed in the context of this pregnancy.

\section{Case report}

A 31-year-old woman with congenital bilateral ovarian agenesis had been diagnosed with the condition at the age of 17 on investigation for primary amenorrhea. Since then, the patient had been receiving oral contraceptive pills for hormonal replacement. In preparation for IVF, a dilatation and curettage was performed, followed by extended estrogen administration for thin endometrium and then IVF embryo transfer with donor eggs. An ectopic pregnancy in the second cycle necessitated a laparoscopic salpingectomy and a dilatation and curettage. In the third cycle, the intrauterine pregnancy was maintained on estradiol and progesterone until 12 weeks after embryo transfer. The pregnancy proceeded uneventfully until 38 weeks and 5 days' gestation, 
when spontaneous rupture of membranes occurred followed by the onset of labor. After 12 hours, the cervix was $4 \mathrm{~cm}$ dilated and fully effaced. Labor was augmented with oxytocin (Syntocinon ${ }^{\circledR}$; Novartis Pharmaceuticals Australia Pty Limited, Sydney, Australia) and the cervix was fully dilated 8 hours later. A normal, healthy baby weighing $3220 \mathrm{~g}$ was born by instrumental delivery as a result of maternal exhaustion. In the third stage, the placenta could not be delivered by cord traction, despite part of the placenta protruding from the external cervical os of the uterus, and there was active bleeding. Manual removal of the placenta was performed in the operation theater but part of the placenta was noticed to be adherent and this was left in situ. Blood loss was estimated to be $2500 \mathrm{~mL}$. Bleeding was controlled with oxytocin infusion, ergometrine maleate (Ergometrine injection; Hospira Australia Pty Ltd, Melbourne, Australia) injection, and misoprostol $\left(\right.$ Cytotec $^{\circledR}$; Pfizer Australia Pty Ltd, Sydney, Australia) per vaginum (PV). Four units of blood and antibiotic prophylaxis were administered.

The PV loss remained minimal and the patient was discharged a week after delivery. She was well until 5 weeks following childbirth when she presented with increasing brownish discharge PV and a low-grade fever. The white cell count was raised to $13.3 \times 10^{9} / \mathrm{L}$ with neutrophilia $\left(11.6 \times 10^{9} / \mathrm{L}\right)$; the platelet count was $210 \times 10^{9} / \mathrm{L}$. A pelvic ultrasound scan showed there was a piece of placenta measuring $8 \times 5 \times 2 \mathrm{~cm}$ remaining in the uterine cavity. There was no vascularity observed between the placenta and the uterine wall on Doppler ultrasound examination. After discussion with the patient, misoprostol was administered vaginally. After a total dose of $2000 \mu \mathrm{g}$ of misoprostol PV, part of the placenta was protruding from the external os of the uterus. The placental tissue was removed manually and the patient was discharged the following day in good condition.

\section{Discussion}

Parturition in humans involves complex mechanisms with key elements such as oxytocin, corticotropin-releasing hormone and urocortin, relaxin, parathyroid hormone-related protein, opioids, neurosteroids, and monoamines. ${ }^{3}$ In the female, relaxin is a protein hormone produced mainly by the corpus luteum of the ovary but also by the breast and, during pregnancy, by the placenta, chorion, and decidua. In animal studies, the removal of activities of relaxin, either by oophorectomy or through administration of neutralizing antibodies, has resulted in prolonged labor and a high fetal mortality rate. This is thought to result from reduced cervical elasticity and defective cervical ripening. ${ }^{4}$ However, the action of relaxin appears to vary among species. ${ }^{5}$ In women with primary ovarian insufficiency (or premature ovarian failure) and absent circulatory relaxin, ${ }^{6}$ cervical dilatation occurs successfully in spontaneous labor, although at a slower rate. $^{7}$ Moreover, no difference was found in the duration of pregnancies in patients who conceived through egg donation compared with standard IVF pregnancies. ${ }^{8}$ In humans, it appears that relaxin does not play a major role in the onset and progression of labor, although there is some evidence to suggest that relaxin may play a role in cervical ripening. ${ }^{9}$ Therefore, elective cesarean section is not indicated in patients with absent or nonfunctioning ovaries.

IVF is known to be associated with an increased incidence of morbidly adherent placenta, with an estimated rate of 16 cases in 1000 IVF pregnancies versus 1.2 cases in 1000 spontaneous pregnancies. ${ }^{2}$ Whether this results from endometrial changes with IVF treatment protocols (dilatation and curettage before IVF) or the characteristics of the gestational carrier (thin endometrium in this patient with bilateral ovarian agenesis), precaution is required in the management of IVF pregnancies if defective decidualization is expected. Since morbidly adherent placenta is associated with significant maternal or fetal mortality or morbidity, screening for and anticipation of this condition may be beneficial in IVF pregnancies ${ }^{10,11}$ and the IVF treatment protocol may need to be reviewed.

Abnormal vascularization is observed at the placental and myometrial or tissue interface in morbidly adherent placenta. ${ }^{11}$ Conservative management without separation of the placenta at delivery has been shown to decrease the blood loss and improve the maternal outcome. ${ }^{10}$ However, there are potential complications of secondary hemorrhage and infection. ${ }^{12,13}$ In this case, the morbidly adherent part of the placenta was managed conservatively. The retained adherent placenta was removed uneventfully at 5 weeks following childbirth when there was no significant flow observed between the placenta and the myometrium on Doppler ultrasound examination. In conservatively managed morbidly adherent placenta, this sign may indicate a safe time for removal of the retained placental tissue when there is a concern for arising complications (eg, infection in this case). Alternatively, arterial embolization and/or ligation could be considered for preservation of subsequent fertility, and ultimately hysterectomy if conservative management fails. ${ }^{13}$

\section{Conclusion}

Spontaneous labor and vaginal delivery can be successful in patients with congenital bilateral ovarian agenesis. In IVF 
pregnancies, screening for and anticipation of morbidly adherent placenta may be beneficial when risk factors for this condition are present. With morbidly adherent placenta, when the blood flow between the placenta and the myometrium is absent it may be a safe time for removal of the adherent placenta.

\section{Disclosure}

The author reports no conflicts of interest in this work.

\section{References}

1. Kadoch IJ, Jamal W, Phillips SJ, et al. Successful pregnancy in an ovarian agenesis patient after modified natural cycle IVF oocyte donation. Reprod Biomed Online. 2009;19:221-223.

2. Esh-Broder E, Ariel I, Abas-Bashir N, Bdolah Y, Celnikier DH. Placenta accreta is associated with IVF pregnancies: a retrospective chart review. BJOG. 2011;118:1084-1089.

3. Petraglia F, Imperatore A, Challis JR. Neuroendocrine mechanisms in pregnancy and parturition. Endocr Rev. 2010;31:783-816.

4. Downing SJ, Sherwood OD. The physiological role of relaxin in the pregnant rat. I. The influence of relaxin on parturition. Endocrinology. 1985;116:1200-1205.
5. Sherwood OD. Relaxin's physiological roles and other diverse actions. Endocr Rev. 2004;25:205-234.

6. Johnson MR, Abdalla H, Allman AC, Wren ME, Kirkland A, Lightman SL. Relaxin levels in ovum donation pregnancies. Fertil Steril. 1991;56:59-61.

7. Eddie LW, Cameron IT, Leeton JF, Healy DL, Renou P. Ovarian relaxin is not essential for dilatation of cervix. Lancet 1990;336:243.

8. Soderstrom-Anttila V, Tiitinen A, Foudila T, Hovatta O. Obstetric and perinatal outcome after oocyte donation: comparison with in-vitro fertilization pregnancies. Hum Reprod. 1998;13:483-490.

9. Kelly AJ, Kavanagh J, Thomas J. Relaxin for cervical ripening and induction of labour. Cochrane Database Syst Rev. 2001:CD003103.

10. Wong HS, Hutton J, Zuccollo J, Tait J, Pringle KC. The maternal outcome in placenta accreta: the significance of antenatal diagnosis and non-separation of placenta at delivery. $N Z$ Med J. 2008;121:30-38.

11. Wong HS, Cheung YK, Zuccollo J, Tait J, Pringle KC. Evaluation of sonographic diagnostic criteria for placenta accreta. J Clin Ultrasound. 2008;36(9):551-559.

12. Bader G, Jelen H, Quarello E, Guyot B, Limot O, Ville Y. Interest of modern imagery for conservative management of a placenta percreta. Gynecol Obstet Fertil. 2007;35(2):142-148.

13. Sentilhes L, Gromez A, Clavier E, Resch B, Verspyck E, Marpeau L. Fertility and pregnancy following pelvic arterial embolisation for postpartum haemorrhage. BJOG. 2010;117(1):84-93.
International Journal of Women's Health

\section{Publish your work in this journal}

The International Journal of Women's Health is an international, peerreviewed open-access journal publishing original research, reports, reviews and commentaries on all aspects of women's healthcare including gynecology, obstetrics, and breast cancer. Subject areas include: Chronic conditions (migraine headaches, arthritis, osteoporosis);

\section{Dovepress}

Endocrine and autoimmune syndromes; Sexual and reproductive health; Psychological and psychosocial conditions. The manuscript management system is completely online and includes a very quick and fair peer-review system. Visit http://www.dovepress.com/ testimonials.php to read real quotes from published authors. 